Revista de
GESTÃOAnal of Integrated
COSTEIRA Integrada COSTAL ZONE MANAGEMENT

\title{
Geoprocessamento aplicado na carcinicultura marinha em São José do Norte, Rio Grande do Sul, Brasil
}

\author{
Rodrigo Randow Freitas ${ }^{\circledR}$, a; Paulo Roberto Armanini Tagliani ${ }^{\text {b }}$ Luís Henrique da Silva Poersch ${ }^{\text {b }}$
}

\begin{abstract}
RESUMO
Considerando o rápido desenvolvimento das atividades relacionadas a aquicultura no mundo, é cada vez mais necessário o uso de métodos visando à seleção de locais potenciais para o seu desenvolvimento. Assim, o presente estudo teve como objetivo definir áreas propícias para o desenvolvimento da carcinicultura marinha em viveiros escavados, na região do baixo estuário da Laguna dos Patos, sul do Brasil. Utilizou-se imagem do satélite Landsat 7 ETM+, órbita-ponto 221-082 de 24/10/2001, com combinação das bandas 1, 2 e 3. A análise espacial foi realizada com o software Idrisi Andes edition ${ }^{\circledR}$ (ver. 15.01 - Clark University). As áreas foram selecionadas a partir da exclusão de áreas legalmente protegidas, seguido de análise multicriterial de atratividade considerando, por exemplo, o custo de oportunidade e a distância de infraestruturas, dentre outros. Como resultado, as áreas consideradas mais atrativas perfazem um total de 5.300 hectares (16,84\%), enquanto 14.600 hectares $(46,78 \%)$ possuem condições consideradas boas. Salienta-se que as áreas consideradas com potencial alto possibilitam um menor investimento na construção dos viveiros.
\end{abstract}

Palavras-chave: Viveiros escavados, Lagoa dos Patos, Sensoriamento Remoto, LANDSAT.

\section{ABSTRACT}

\section{Geoprocessing applied to marine shrimp farming in São José do Norte, Rio Grande do Sul, Brazil}

Considering the rapidly developing aquaculture in the world, is increasingly necessary to use methods aimed at the selection of potential sites for a variety of aquaculture activities Thus, the present study in order to define areas suitable for the development of marine shrimp earth ponds culture in the lower estuary of the Patos Lagoon, southern Brazil. We used Landsat 7 image ETM+ satellite, 221-082 point-orbit of 24/10/2001, with the combination of bands 1, 2 and 3. Spatial analysis was performed with the software Idrisi Andes Edition ${ }^{\circledR}$ (ver. 15.01-Clark University). The areas were selected from the exclusion of legally protected areas, followed by attractiveness multicriteria analysis, considering for example the opportunity cost and distance from infrastructure, among others. As a result, a total of 5,300 hectares (16.84\%) were considered most attractive, while 14,600 hectares (46.78\%) are considered in good conditions. Thus, it should be noted that the areas considered enabling a high potential and smaller investment in the construction of farms (hours/machine).

Key words: Earth Ponds farm, Patos Lagoon, Remote Sensing, LANDSAT

\footnotetext{
(a) Corresponding author to whom correspondence should be addressed.
}

${ }^{a}$ Universidade Federal do Espírito Santo, Centro Universitário Norte do Espírito Santo, Departamento de Engenharias e Tecnologia, Laboratório de Gestão Costeira - Aquicultura e Pesca (LGCap). Rodovia BR 101 Norte, Km 60, Bairro Litorâneo, CEP, São Mateus, Espírito Santo, Brazil. E-mail: <digorandow@gmail.com>

${ }^{\mathrm{b}}$ Universidade Federal do Rio Grande, Instituto de Oceanografia, Laboratório de Oceanografia Geológica, 96201-900 Rio Grande, RS, Brasil. e-mails: Tagliani < paulotagliani@furg.br>; Poersch <lpoersch@mikrus.com.br>

* Submission: 28 AUG 2014; Peer review: 25 SEP 2014; Revised: 5 NOV 2014; Accepted: 10 DEC 2014; Available on-line: 11 DEC 2014
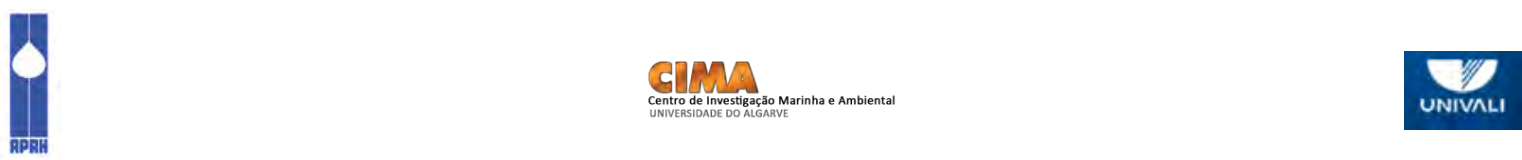


\section{Introdução}

Considerando o franco desenvolvimento da aquicultura no mundo, cada vez mais é necessária a utilização de métodos que visem a seleção de locais propícios para as mais variadas atividades aquícolas (McLeod et al., 2002; Pérez et al., 2002; Karthik et al., 2005; Hossain et al., 2007; Longdill et al., 2008). Dentre os diversos ramos desta atividade, os mais praticados são a criação de ostras (ostreicultura), peixes (piscicultura), rãs (ranicultura), camarões (carcinicultura), entre outros (Pullin et al., 1993).

No Brasil, o cultivo comercial de camarões marinhos teve início nos anos 70, baseando-se em tecnologias importadas com alguns aprimoramentos, mas somente na década de 80 adquiriu-se um caráter realmente empresarial (Barbieri Júnior \& Neto, 2002, Moles \& Bunge, 2002). No entanto, as escolhas de áreas para o cultivo consideravam principalmente os interesses do produtor e nem sempre estavam de acordo com critérios técnicos e ambientais.

Além disso, de maneira semelhante ao que aconteceu nos países que dominam atualmente o mercado mundial da carcinicultura (China, Tailândia, Vietnã, Índia, Indonésia e Bangladesh), o ritmo de expansão da atividade vem ocorrendo de forma acelerada, aumentando sua participação de 3\% (43.762 toneladas) em 1977, para $51 \%$ (3.275.726 toneladas) em 2007, superando a pesca extrativa. Somando isso ao fato do país dominar as novas tecnologias de produção, faz com que seja o principal produtor de camarões das Américas (FAO, 2010).

$\mathrm{Na}$ região Sul, devido à necessidade de adaptação às temperaturas mais amenas, o cultivo de camarões sempre esteve focado nas espécies nativas, mas a falta de um pacote tecnológico específico para as espécies impossibilitou a viabilidade econômica de sua produção. Assim, a partir do sucesso do cultivo da espécie Litopenaeus vannamei na região Nordeste, os produtores da região Sul, principalmente de Santa Catarina, decidiram pela utilização dessa espécie para o desenvolvimento da atividade (Poersch et al., 2006).

Com os avanços no desenvolvimento da atividade, produtores do Rio Grande do Sul, começaram a investir na atividade em meados de 2002, com a introdução da nova espécie, embora ainda sejam poucos os produtores no estado. Conforme Poersch et al., (2006), devido às características ambientais e pelos menores custos de implantação, o estuário da Lagoa dos Patos vem sendo a área preferida para implantação destes empreendimentos, com destaque para a primeira fazenda produtora de camarões marinhos, localizada no município de São José do Norte

Entretanto, com o potencial para o crescimento produtivo da carcinicultura na região, surge concomitantemente um real aumento dos riscos de impactos ambientais e socioeconômicos. Isso associado ao fato do gerencia mento das zonas costeiras apresentarem um elevado grau complexidade, devido a grande variedade de mudanças causadas pelos impactos do desenvolvimento regional/urbano e a exploração dos recursos naturais (Völcker \& Scott, 2008).

Cabe ressaltar que problemas semelhantes foram relatados em países onde a atividade cresceu exponencialmente e com consequente descontrole produtivo, legal e ambiental (FAO, 1997; Poli et al., 2000; Pérez et al., 2002; Chen et al., 2005; Giap et al., 2005; Karthika et al, 2005; Beltrame et al., 2006; Primavera, 2006; Freitas et al., 2009).

Assim, no processo de planejamento do desenvolvimento da atividade de carcinicultura, a análise espacial constitui um elemento de grande importância, possibilitando identificar possíveis conflitos de uso dos recursos costeiros, minimizar impactos ambientais e socioeconômicos, além de permitir uma alocação mais eficiente do espaço reduzindo os custos de oportunidade (Corbin \& Young, 1997; GESAMP, 2000; Rajitha et al., 2007).

Dessa forma, a utilização de Sistemas de Informações Geográficas (SIG) no processo de planejamento e ordenamento das atividades existentes na região costeira, permite uma integração do processamento digital das imagens de sensores remotos com a análise espacial, facilitando a organização espacial das informações (Souto \& Amaro, 2005).

Assim, juntamente com dados de classificação de uso do solo, de análises biológicas, geográficas e socioeconômicas, as informações obtidas podem ser utilizadas como base para classificar as áreas para implantação e desenvolvimento da atividade de carcinicultura, gerando menores impactos socioambientais, conservando áreas protegidas e beneficiando os investidores com melhorias na produtividade (Freitas \& Tagliani, 2007; Giap et al., 2005; Souto \& Amaro, 2005).

Vale ressaltar que as geotecnologias são constantemente utilizadas por diversos trabalhos em diferentes regiões do Brasil, incluindo a identificação de ecossistemas através do mapeamento e monitoramento das zonas áreas costeiras (Prost, 2001; Moura et al., 2002; Camargo et al., 2003; Crepani \& Medeiros, 2003; Kampel et al., 2005; Ucha, et al., 2011).

Considerando o que foi exposto, o presente estudo se propõe a identificar locais apropriados para o desenvolvimento da carcinicultura marinha em viveiros escavados, na região do baixo estuário da Laguna dos Patos, no município de São José do Norte/RS, através de técnicas de SIG.

\section{Material e métodos}

\subsection{Descrição da área de estudo}

A área de estudo compreende o município de São José do Norte, (Latitude/Longitude: $-31.5^{\circ} /-51.5^{\circ}$ ), Estado 
do Rio Grande do Sul, Brasil, localizada na parte sul do estuário da Laguna dos Patos, zona costeira do Atlântico Sul (Figura 1).

Predominantemente, a economia local está voltada à pesca artesanal, comércio e atividades agropastoris (bovinos, ovinos, cultivo de cebola e arroz), todas em pequena escala e/ou de subsistência. Também podem ser observadas grandes áreas de plantio intensivo de pinus (Pinus elliottii), destinados à produção de madeira e extração de resina (Tagliani \& Vicens, 2003; Gianuca \& Tagliani, 2012).

A topografia é essencialmente caracterizada por terras baixas, banhados marginais, dunas e praias litorâneas, apresentando pouca variação na declividade $(0-5 \%)$. Na região estão presentes grandes extensões de banhados que formam parte da fisionomia natural do município, geralmente margeando as lagoas e fazendo a transição destas com as outras formações. (Tagliani \& Vicens, 2003).

Quanto às dunas, estas se distribuem paralelamente a linha de costa e são constituídas essencialmente por areias de granulometria fina (Oliveira \& Calliari, 2006), que recebem aporte de sedimentos oriundos da Laguna dos Patos (Figueiredo \& Calliari, 2006). Em relação aos campos litorâneos, resultantes da erosão eólica sobre as dunas costeiras, compreendem grandes áreas e apresentam elevada colonização por vegetação nativa e exótica, quando comparada a outros ambientes da região (Tagliani \& Silva, 2011). Em geral a região apresenta solos férteis (embora tenha altos teores de sais e sódio e apresentar solo arenosos) e observa-se nesses ambientes um predomínio da rizicultura, pecuária extensiva, cultivos de cebola, reflorestamentos com uso intensivo do solo, além de herbáceas (Tagliani \& Vicens, 2003).

Em relação às marismas, estas ocupam margens e pequenas ilhas do estuário, tendo como característica a tolerância às variações de salinidade e inundações irregulares. As comunidades vegetais desempenham importante papel na estabilidade do substrato, impedindo a erosão e representam o habitat de diversos organismos (Cordazzo \& Seeliger, 1988).

\subsection{Coleta e tratamento das informações espaciais}

A análise espacial foi realizada a partir de imagens do satélite LANDSAT 7 sensor ETM+, com resolução geométrica de 30 metros, órbita-ponto 221-082 de 24/10/2001 às 13:07, com combinação das bandas 1,2 e 3 utilizada no software Idrisi Andes edition ${ }^{\circledR}$ (v. 15.01Clark University), para a digitalização das informações espaciais diretamente na tela do computador.

O estudo priorizou a utilização de imagens de boa resolução obtidas gratuitamente na internet, através do catálogo de imagens no site do Instituto Nacional de Pesquisas Espaciais (INPE). A imagem selecionada apre- senta boa visibilidade devido à baixa cobertura de nuvens em todos os quadrantes $(10 \%)$.

Assim como Freitas et al. (2009), utilizando o módulo resample no SIG, foi realizado o georreferenciamento da imagem obtida e a partir dessa, foi realizada a digitalização e separação em 9 camadas de todas as feições de interesse na área de estudo (Figura 1). Praticamente toda área de estudo é representada por apenas quatro camadas de informação: campos litorâneos, dunas, banhados e áreas de reflorestamento. Os polígonos de cada uma foram digitalizados utilizando a imagem georreferenciada como base e posteriormente cada camada foi transformada do formato vetorial para raster, compondo o banco de dados final.

Mapas temáticos (escala de 1:600.000) separados em camadas individuais, tais como tipos de solos, capacidade de uso, vegetação, corpos hídricos e vias públicas, foram submetidos a rotinas específicas de geoprocessamento no SIG Idrisi Andes e integrados a um modelo de caracterização/identificação, construído para esse estudo, como descrito abaixo.

\subsection{Identificação dos critérios para seleção de áreas}

Diferentes critérios para seleção de áreas apropriadas ao cultivo de camarão têm sido utilizados em diversos estudos, sendo mais utilizados os que consideram fatores socioeconômicos, solo, clima, topografia, disponibilidade de água, infraestrutura e logística (Salam et al., 2005; Giap et al., 2005; Beltrame et al., 2006; Hossain et al., 2007; Radiarta et al., 2008). No presente estudo, primeiramente foram utilizados critérios restritivos (áreas de proteção ambiental, Unidades de Conservação, etc.) para criar áreas de exclusão (inaptas) (Figura 2).

Após a definição dos critérios restritivos, os mesmos foram espacializados por meio de rotinas específicas do SIG (Função Buffer), criando zonas tampão (Tabela 1). Isso foi possível através da superposição das áreas com restrição legal (módulo Overlay), sendo gerada uma imagem única, onde o valor " 1 " representa as áreas sem restrição e "0" as áreas com restrição. Para as área sem restrição foi calculada a área disponível a fim de excluir as áreas menores que 1 hectare da análise, economicamente inviáveis (Freitas et al., 2009).

Conforme Vitalli et al., (2009), zonas tampão são áreas ao redor de regiões consideradas inaptas à uma determinada atividade, de modo a reduzir os a probabilidade de impactos à essas regiões. Assim, utilizando os critérios de exclusão de áreas protegidas e com características ambientais (tipo de solo e salinidade) ou de infraestrutura inaptas para atividade, resultou em uma imagem indicando as áreas aptas e não aptas (Figura 2).

A criação de zonas tampão foi utilizada por Torres e Andrade (2010) em estudo para determinação de áreas para instalação de empreendimentos de piscicultura ma- 


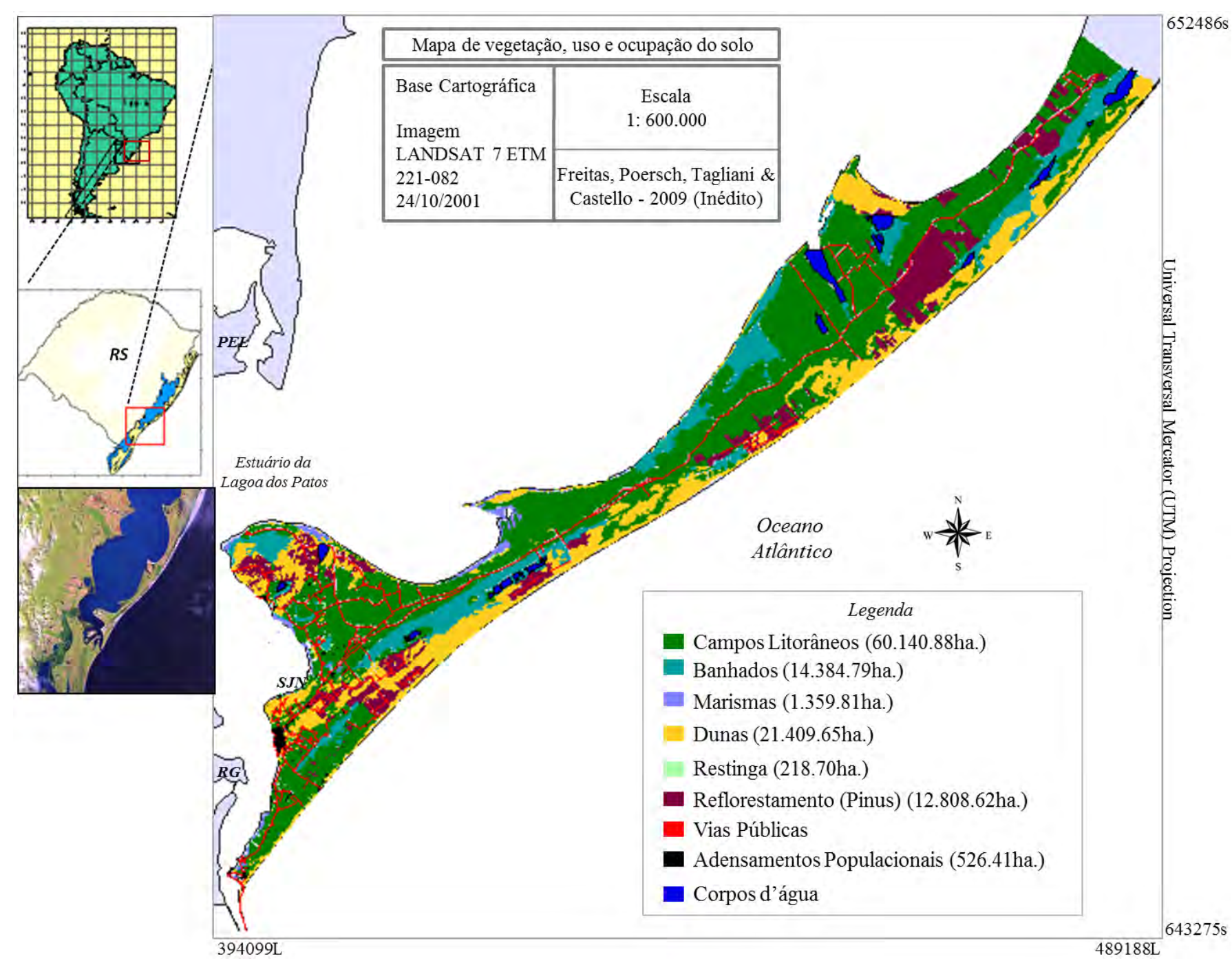

Figura 1 - Mapa de vegetação, uso e ocupação do solo no estuário da Lagoa dos Patos.

Figure 1 - Vegetation map, use and land occupation in Patos Lagoon estuary.

rinha. Estas zonas tampão seriam áreas de amortecimento ou proteção, onde não seria permitida a instalação de empreendimentos aquícolas e que servem para evitar conflitos com outras atividades.

Além da criação de zonas tampão, observou-se nesse estudo, a necessidade de se criar uma "zona de exclusão" para o critério salinidade, justificando-se pelo fato de ali representar a zona limite do estuário da Lagoa dos Patos (Peixoto et al., 2005). Em função deste fator, não é recomendada a instalação de nenhum empreendimento fora da zona estuarina. Mesmo ocasionalmente com os ventos do quadrante sul ampliando a área de influência da água marinha.

Cabe salientar que a zona estuarina está localizada na porção sul da Lagoa dos Patos, segundo Capítoli \& Bemvenuti (2004), delimitada ao norte por uma linha imaginária traçada entre a Ponta da Feitoria $\left(31^{\circ} 42^{\prime} \mathrm{S}\right.$ e $\left.52^{\circ} 02^{\prime} \mathrm{W}\right)$ e a Ponta dos Lençóis $\left(31^{\circ} 48^{\prime} \mathrm{S}\right.$ e $\left.51^{\circ} 50^{\prime} \mathrm{W}\right)$ e ao sul pelos molhes da Barra $\left(32^{\circ} 11^{\prime} \mathrm{S}\right.$ e $\left.52^{\circ} 04^{\prime} \mathrm{W}\right)$. Porém, em anos atípicos como os proporcionados pelo fenômeno climático La Niña, este limite pode se estender mais ao norte. Por outro lado, em anos de El Niño, a zona estuarina pode migrar para a porção sul (Möller \& Fernandes, 2010).

Outro motivo da criação dessa zona de exclusão foi a presença de grande extensão de cultivos de arroz. Pelo fato de ser uma atividade já consolidada e por ser considerada uma importante fonte de renda na região, buscou-se assim evitar possíveis conflitos de uso.

Com relação à incorporação de áreas para atividades aquícolas, esta deve ser realizada com cautela para se evitar o senso comum de que a carcinicultura afeta mais a segurança alimentar e poluição de ecossistemas, do que a geração de renda e produção de alimentos. Rajitha et al. (2007) e Gowing \& Ocampo-Thomason (2007), observaram a conversão de áreas destinadas à agricultura, principalmente cultivos de arroz, em viveiros de camarão em várias partes do globo. 


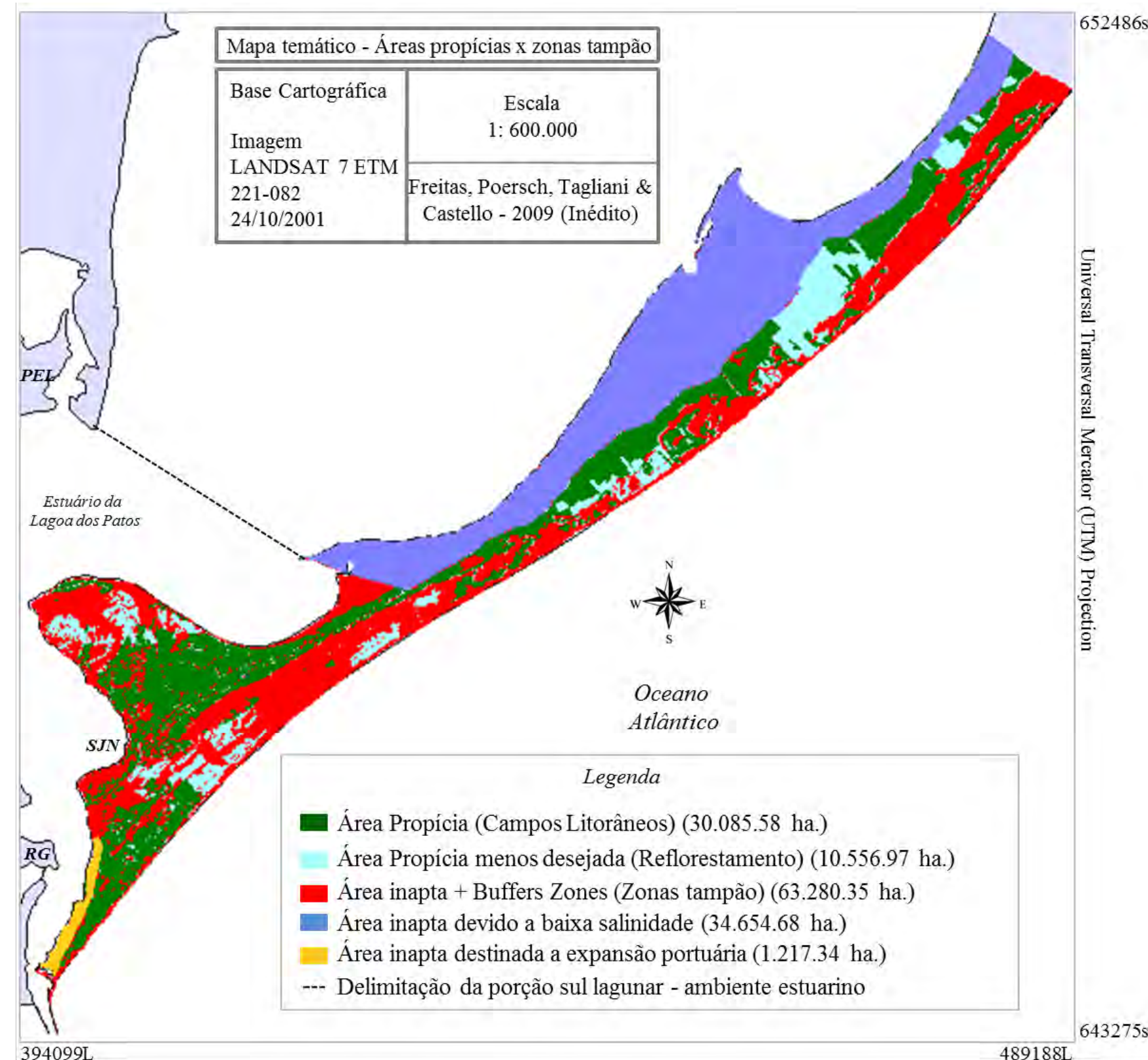

Figura 2 - Mapa temático de zonas de exclusão legal e ambiental.

Figure 2 - Thematic map of legal and environmental exclusion areas.

Hossain et al. (2007) em estudos realizados em Bangladesh, apresentam uma visão um pouco diferente, relatando que pastagens subutilizadas exclusivamente por búfalos e bovinos poderiam ser convertidas em pisciculturas, tendo um benefício ambiental e econômico muito maior. Prein e Ahmed (2000) descrevem que em muitos países da África, a "estação da fome" é comum e em tais épocas, que são recorrentes, ocorrem períodos de estresse familiar grave.

Assim, empreendimentos aquícolas podem ser idealizados e planejados para fornecer alimento para combater a baixa oferta usual de nutrientes essenciais. De qualquer forma, a possibilidade de desenvolvimento e diversificação da atividade econômica e a decisão de converter pastagem em áreas aquícolas, estão inteiramente relacionadas à segurança alimentar e aspectos sociais.

Outro exemplo comparando a carcinicultura com o cultivo da espécie do gênero Eucalyptus ssp (comum na região), que apresenta altíssimo nível de melhoramento genético, produtividade e qualidade da madeira. Contudo, utilizando ferramentas econômicas para análise e comparação dos investimentos entre as atividades madeireiras e aquícolas, por exemplo, a análise da Taxa Interna de Retorno (TIR), tem-se que, mesmo com a alta produtividade e qualidade da madeira, tem-se uma maior viabilidade econômica por parte da aquicultura, isso com diferença de mais de 6\%. Entretanto, observa- 
Tabela 1 - Considerações sobre a seleção dos critérios de atratividade e restrição adotada para cultivos de camarões marinhos em viveiros escavados.

Table 1 - Considerations about the criteria selection of attractiveness and constraint adopted for marine shrimp earth ponds farms.

\begin{tabular}{|c|c|c|}
\hline Critérios & Atratividade (factors) & Restritivos (constraint) \\
\hline \multicolumn{3}{|c|}{ Ambientais } \\
\hline Temperatura & $\begin{array}{l}\text { Verão e Primavera com temperatura média superi- } \\
\text { or a } 25^{\circ} \mathrm{C} \text { durante a fase final de engorda (Peixoto } \\
\text { et al. 2005). }\end{array}$ & $\begin{array}{l}\text { No inverno e outono, o cultivo de } L \text {. vannamei é } \\
\text { afetado por temperaturas menores que } 19^{\circ} \mathrm{C} \text { (Pei- } \\
\text { xoto et al., 2005). }\end{array}$ \\
\hline Salinidade & $\begin{array}{l}15-25(18-22) \text { (Barbieri \& Neto, 2002; Poli et } \\
\text { al., 2000) }\end{array}$ & $\begin{array}{l}\text { Valores }<10 \text { ou }>25 \text { (Barbieri \& Neto, 2002; Poli } \\
\text { et al. 2000) }\end{array}$ \\
\hline $\begin{array}{l}\text { Declividade/Ele- } \\
\quad \text { vação }\end{array}$ & $\begin{array}{l}\text { Localmente está entre } 0 \text {-5\% (Tagliani \& Vicens, } \\
\text { 2003). É considerada aceitável entre } 1 \text { - 10m acima } \\
\text { do nível do mar. (Barbieri \& Neto, 2002; Giap et } \\
\text { al., 2005; Hossain et al., 2007) }\end{array}$ & $\begin{array}{l}\text { Declividade acentuada. }>10 \mathrm{~m} \text {. (Giap et al., 2005; } \\
\text { Hossain } \text { et al., 2007) }\end{array}$ \\
\hline Tipo de Solo & $\begin{array}{l}\text { Conteúdo de argila em torno de } 15-25 \% \text {; alta plas- } \\
\text { ticidade; teores baixos ( } 2-4 \% \text { ) ou médios de maté- } \\
\text { ria orgânica e ph próximo ao neutro. Solos não or- } \\
\text { gânicos (arenosos, argilosos ou argilo-arenosos) } \\
\text { com boa capacidade de agregação. (Barbieri \& Ne- } \\
\text { to, 2002; Poli et al., } 2000 \text { ) }\end{array}$ & $\begin{array}{l}\text { Solos ricos em matéria orgânica (cerca de } 20 \% \text { ); } \\
\text { solos sulfurosos-ácidos (orgânicos tiomórficos). } \\
\text { (Barbieri \& Neto, 2002; Giap et al., 2005) }\end{array}$ \\
\hline $\begin{array}{l}\text { Direção e Regime } \\
\quad \text { de vento }\end{array}$ & $\begin{array}{l}\text { Localmente é forte o regime de ventos provenien- } \\
\text { tes do quadrante nordeste durante o período de ve- } \\
\text { rão, com velocidade média entre } 3,6 \text { e } 5,1 \mathrm{~m} / \mathrm{s} \\
\text { (Garcia 1998). Assim, é garantindo uma boa mo- } \\
\text { vimentação das águas superficiais e elevação dos } \\
\text { níveis de oxigênio dissolvido na água nos viveiros } \\
\text { (Peixoto et al., 2005). }\end{array}$ & $\begin{array}{l}\text { Ausência ou diminuição acentuada de/prolongada } \\
\text { da ação de ventos. }\end{array}$ \\
\hline $\begin{array}{l}\text { Capacidade de Uso } \\
\text { (Classe de Solo) }\end{array}$ & $\begin{array}{l}\text { Solos preferencialmente de classe }>V \text {, preservan- } \\
\text { do solos nobres para agricultura. Custo de oportu- } \\
\text { nidade menor possível. }\end{array}$ & Classe de solo $<\mathrm{V}$ \\
\hline Vegetação & $\begin{array}{l}\text { Campos Litorâneos e/ou Dunas obliteradas. (Peixo- } \\
\text { to et al., 2005) }\end{array}$ & $\begin{array}{l}\text { Áreas de proteção ambiental (Marisma, banhado, } \\
\text { restinga e dunas). Também deverão ser criadas } \\
\text { zonas tampão "Buffer" de } 15 \mathrm{~m} \text { a partir das APP } \\
\text { (Lei Fed. No } 4771 / 1965 \text { código florestal). }\end{array}$ \\
\hline $\begin{array}{l}\text { Disponibilidade } \\
\text { de água } \\
\text { (Acesso) }\end{array}$ & $\begin{array}{l}\text { Excelente condição: } 100 \text { - } 1000 \mathrm{~m} \text {; Boa: } 1000- \\
2000 \mathrm{~m} \text {; e na margem do aceitável (Razoável): } \\
2000 \text { - } 3000 \mathrm{~m} \text { (Beltrame et al., 2006; Giap et al., } \\
2005)\end{array}$ & $\begin{array}{l}\text { Áreas não recomendadas com distância }>3000 \mathrm{~m} \\
\text { (Beltrame } \text { et al., 2006; Giap et al., 2005). Deverá } \\
\text { ser criada uma zona tampão "Buffer" de } 30 \mathrm{~m} \text { pa- } \\
\text { ra cursos d'água }<10 \mathrm{~m} \text { de largura e } 100 \mathrm{~m} \text { além } \\
\text { da área sujeita a alagamento sazonal da Lagoa dos } \\
\text { Patos. (Lei Fed. No } 4771 / 1965 \text { código florestal). }\end{array}$ \\
\hline
\end{tabular}

\begin{tabular}{cll}
\hline Critérios & \multicolumn{1}{c}{ Atratividade (factors) } & Restritivos (constraint) \\
\hline & \multicolumn{1}{c}{ Socioeconômicos e Logística / Infraestrutura } \\
\hline & Disponível e Perto do empreendimento (Poli et al., \\
& 2000) Excelente condição: $1-200 \mathrm{~m}$; Boa: $200-\quad$ Inexistente e Longe do empreendimento (Áreas \\
Eletrificação & $500 \mathrm{~m}$; e na margem do aceitável (Razoável): $500-$ & não recomendadas com distância $>750 \mathrm{~m})$. \\
& $750 \mathrm{~m}$ (Salam et al., 2005; Hossain et al., 2007).
\end{tabular}

Boa dirigibilidade; Para estradas não pavimentadas - Excelente condição: 15 - 500m; Boa: 500 Vias públicas $\quad 1000 \mathrm{~m}$; e na margem do aceitável (Razoável): 1000 - 2000m (Giap et al., 2005; Salam et al., 2005; Hossain et al.. 2007)
Estado ruim de conservação e áreas não recomendadas com distância > 2000 m (Giap et al., 2005; Salam et al., 2005; Hossain et al., 2007). Também deverão ser criadas zonas tampão de $15 \mathrm{~m}$ a partir das vias públicas (Lei Fed. Nº766/1979 art. $4^{\circ}$ inciso III) 
Tabela 1 - Considerações sobre a seleção dos critérios de atratividade e restrição adotada para cultivos de camarões marinhos em viveiros escavados. (Cont.)

Table 1 - Considerations about the criteria selection of attractiveness and constraint adopted for marine shrimp earth ponds farms. (Cont.)

\begin{tabular}{|c|c|c|}
\hline Critérios & Atratividade (factors) & Restritivos (constraint) \\
\hline \multicolumn{3}{|c|}{ Socioeconômicos e Logística / Infraestrutura } \\
\hline Poluição & $\begin{array}{l}\text { Locais com boa qualidade de água e solo e distân- } \\
\text { cia }>100 \text { m de edificações e outros empreendimen- } \\
\text { tos aquícolas (autores). }\end{array}$ & $\begin{array}{l}\text { Distância }<100 \mathrm{~m} \text { de edificações e outros empre- } \\
\text { endimentos aquícolas. }\end{array}$ \\
\hline $\begin{array}{l}\text { Mercado consu- } \\
\text { midor e Mão de } \\
\text { obra disponível }\end{array}$ & $\begin{array}{l}\text { Distância de mercado consumidor = Excelente } \\
\text { condição: 1000-2000 m; Boa: 2000- } 4000 \mathrm{~m} \text {; Na } \\
\text { margem do aceitável > } 4000 \mathrm{~m} \text { (Giap et al., 2005; } \\
\text { Salam et al., 2005; Hossain et al., 2007). Densida- } \\
\text { de populacional por km }{ }^{2}=\text { Excelente condição: } \\
<500 \text {; Boa: 500-1000; aceitável 1000-2000 (Giap } \\
\text { et al., 2005; Hossain et al., 2007). }\end{array}$ & $\begin{array}{l}\text { Mercado consumidor distante e mão de obra não } \\
\text { disponível localmente (Áreas não recomendadas } \\
\text { com distância }>2000 \mathrm{~m} \text { ) (Giap et al., 2005; Hos- } \\
\text { sain et al., 2007). A recomendação somente se } \\
\text { aplica se houver um acondicionamento satisfató- } \\
\text { rio do produto (incluem-se caminhão frigorífico, } \\
\text { gelo, manuseio e caixas). }\end{array}$ \\
\hline $\begin{array}{l}\text { Serviços disponi- } \\
\text { veis (insumos e } \\
\text { maquinário) }\end{array}$ & $\begin{array}{l}\text { Disponível localmente. Distância da larvicultura = } \\
\text { Excelente condição: }<4000 \text { m; Boa: } 4000-8000 \text { m; } \\
\text { Na margem do aceitável >8000 m (Giap et al., } \\
\text { 2005; Buitrago et al., 2005). }\end{array}$ & Não disponível localmente. \\
\hline $\begin{array}{l}\text { Conflitos por es- } \\
\text { paço e uso }\end{array}$ & $\begin{array}{l}\text { Distante de áreas de pesca, áreas protegidas (APP), } \\
\text { áreas de expansão portuária, agropastoril, urbana, } \\
\text { industrial e de reflorestamento (Buitrago et al., } \\
\text { 2005). }\end{array}$ & $\begin{array}{l}\text { Próximo ou em áreas protegidas (APP), áreas de } \\
\text { pesca, áreas de expansão portuária, agropastoril, } \\
\text { urbana, industrial e de reflorestamento. }\end{array}$ \\
\hline
\end{tabular}

se quanto à produtividade entre atividades, temos $31,5 \mathrm{~m}^{3} /$ ha de madeira roliça empilhada por ano, enquanto a mesma área produziria $7.300 \mathrm{~kg}$ de peixe, por exemplo, em 10 meses (Baena, 2005).

Para se evitar uma simples classificação de áreas aptas e não aptas, foi aplicada uma escala espacial de atratividade com base nos critérios de distância de recursos hídricos, de vias públicas e de capacidade de uso do solo (Kapetsky et al., 1988; Salam et al., 2003).

Com relação à distância de vias públicas, esse critério também foi utilizado para evitar problemas com escoamento da produção e aquisição de insumos (Salam et al., 2005). A construção desse critério tomou como base principal a rodovia BR-101 que cruza o município de norte a sul, bem como estradas vicinais com ou sem pavimento. Sendo que, as estradas foram avaliadas como sendo de boa dirigibilidade, mesmo as não pavimentadas.

Além disso, Hossain et al. (2007) observaram que a escolha do tipo de solo é de grande importância no momento da construção de viveiros. Por exemplo, solos muito permeáveis são menos adequados para viveiros escavados, devido à perda de água por infiltração, aumento na demanda por água e bombeamento, com inevitável incremento nos custos produtivos.

Em relação ao critério capacidade de uso do solo, empregou-se o sistema adaptado por Lepsch et al. (1983), especificamente a classificação por classes (I a VIII), que indica o grau de limitação ao uso agrícola da terra. Na classe I não há nenhum grau de limitação e de forma crescente, na classe VIII, observa-se as terras com mais altos graus de restrições. Cunha et al. (1996) ressalta que o principal fator restritivo dessas áreas para o uso agrícola é a má drenagem, propiciando apenas a cultura de cebola.

Devido à importância de alguns critérios descritivos, tais como poluição, eletrificação, temperatura do ar, dentre outros descritos na tabela 1 , mesmo não sendo espacializados, estes servem de informação complementar na análise final (Frankic, 1998). Por último, após análise em laboratório, foram realizadas saídas de campo na região estudada para verificações in loco das informações obtidas por meio das imagens de satélite.

\section{Resultados e Discussão}

Os resultados obtidos no presente estudo apontaram as áreas propícias e as consideradas não aptas para o cultivo de camarões marinhos em São José do Norte, confirmando o potencial aquícola da atividade no município. Estas informações servirão de suporte para o ordenamento da atividade, já que a maioria dos estudos voltados para determinação de áreas para aquicultura usam apenas mapas simples, cujas informações para tomadas de decisão dos investidores, órgãos de financiamento ou poder público são pouco conclusivas (AguilarManjarrez \& Ross 1995). 
Assim, com a crescente importância de se explorar racionalmente os recursos naturais e com isso minimizar problemas de utilização dos recursos costeiros, primeiramente buscou-se agrupar os usos e cobertura atual do solo do município em classes distintas, que incluem: campos litorâneos, áreas alagáveis (banhados), marismas, dunas, mata de restinga, áreas de reflorestamento de pinos, vias públicas, área construída e corpos d'água (Figura 1).

Considerando que as áreas propícias para desenvolvimento de cultivos de camarões são os campos litorâneos, como resultado da análise inicial obteve-se cerca de 30.000 hectares disponíveis para a atividade. Se considerarmos também as áreas utilizadas hoje para reflorestamento, obteremos pouco mais de 40.000 ha que poderiam ser considerados propícios para a atividade. Este total representa praticamente $40 \%$ da área total do estudo (Figura 2).

Por outro lado, a partir da definição das feições de interesse na área de estudo e criadas as chamadas zonas tampão, como resultado obteve-se quase cem mil hectares de áreas destinadas à preservação/conservação ou não aptas para o cultivo de camarões (Figura 2).

Quanto às áreas caracterizadas com a presença de reflorestamento (Pinus), estas foram classificadas como propícias, mas com a ressalva de que são consideradas menos desejáveis no tocante a implantação da atividade. $\mathrm{O}$ motivo dessa separação também segue a premissa de ser uma atividade já consolidada e por ser considerada uma importante fonte de renda na região, buscando-se assim evitar possíveis conflitos de uso. Mesmo assim representam um importante espaço territorial que pode ser destinado, no futuro, para a implantação / desenvolvimento da carcinicultura marinha.

Em relação ao uso do critério capacidade de uso, o estudo buscou utilizar somente áreas com classe maior do que $\mathrm{V}$, que possuem características impróprias para a agricultura ou que demandariam maiores investimentos para sua correção. Cunha et al (1996) ressalta que o principal fator restritivo dessas áreas para o uso agrícola é a má drenagem, propiciando apenas a cultura de cebola. Como resultado final desse mapa temático, cerca de 19.000 hectares foram considerados como mais recomendados $(64,40 \%)$ e cerca de 10.000 como menos desejados $(35,60 \%)$, conforme a Figura $3 \mathrm{~A}$.

Quanto à utilização do critério tipo de solo (Tabela 1), procurou-se somente utilizar áreas com características de solo compatíveis com a atividade (arenosos, argilosos ou argilo-arenosos), excluindo áreas com teor orgânico elevado e que não são indicadas para a construção de viveiros (Barbieri Júnior \& Neto, 2002; Peixoto et al., 2005). Assim, quase 24.000 hectares foram considerados impróprios para o desenvolvimento da atividade (Figura 3B).
Assim, no presente estudo observou-se que as áreas com alto teor orgânico representaram essencialmente locais com presença de vegetação de marisma, banhados e áreas próximas a corpos d'água. Essas áreas já tinham sido postas anteriormente como zonas tampão, isto é, excluídas das áreas aptas (Figura 1). Essa etapa da análise mostrou aos autores que a construção dos buffers anteriormente se mostrou apropriada.

A partir da definição das áreas propícias, utilizou-se o critério referente a distância da fonte de água (Lagoa dos patos e Oceano Atlântico) para locais destinados a construção de viveiros (Figura 4A). Justifica-se a utilização deste critério devido aos altos custos de captação e construção do sistema de distribuição de água em um empreendimento aquícola. Fato que pode vir a inviabilizar a implantação e desenvolvimento do mesmo (Lee \& Wickins, 1997).

Corroborando com a necessidade de inclusão desse critério em estudos de seleção de áreas aquícolas, a disponibilidade e qualidade de água é o critério ambiental mais importante a se analisar (Pérez et al., 2003; Dennis et al., 2003; Salam et al., 2005). Por exemplo, em um estudo de planejamento da aquicultura realizado no $\mathrm{Vi}$ etnam, Giap et al. (2005) consideraram esse fator como de grande relevância.

Como resultado obteve-se, para o critério áreas propícias versus distância de fonte de água, mais de 4.500 ha com condições excelentes para implantação da atividade (12,79\% do total das áreas propícias). Outros 6.800 ha $(19,39 \%)$ foram considerados com boa condição para implantação de cultivos e 7.500 ha considerados na margem do aceitável $(21,22 \%)$. O restante da área, pouco mais de 16.000 hectares $(46,6 \%)$, foi avaliada como não recomendadas para a aquicultura (Fig. 4A).

Assim, quando analisamos o critério áreas propícias versus distância de vias públicas, pouco menos de 14.000 ha foram considerados com condições excelentes para implantação da atividade $(44,30 \%)$. Cerca de 7.500 ha com boa condição $(23,81 \%)$ e 5.800 ha considerados na margem do aceitável $(18,40 \%)$. Por último, áreas avaliadas como não recomendadas constituíram mais de 4.200 ha (13,49\%), Fig. 4B.

Quando comparada a área total descrita em excelente condição para a atividade na região com outros estudos, observamos que a quantidade em hectare encontrada é considerável. Por exemplo, Giap et al. (2005) relatam que em seu estudo na província de Haiphong no Vietnam, estimou-se que cerca de 30\% (2.604 ha) do total da área disponível, foi altamente apropriada para cultivo de camarões. Principalmente em se tratando que a área existente já utilizada para o cultivo era de apenas 1.690 ha.

Quanto a grande fração encontrada como não recomendada pelo critério distância para a captação de água 


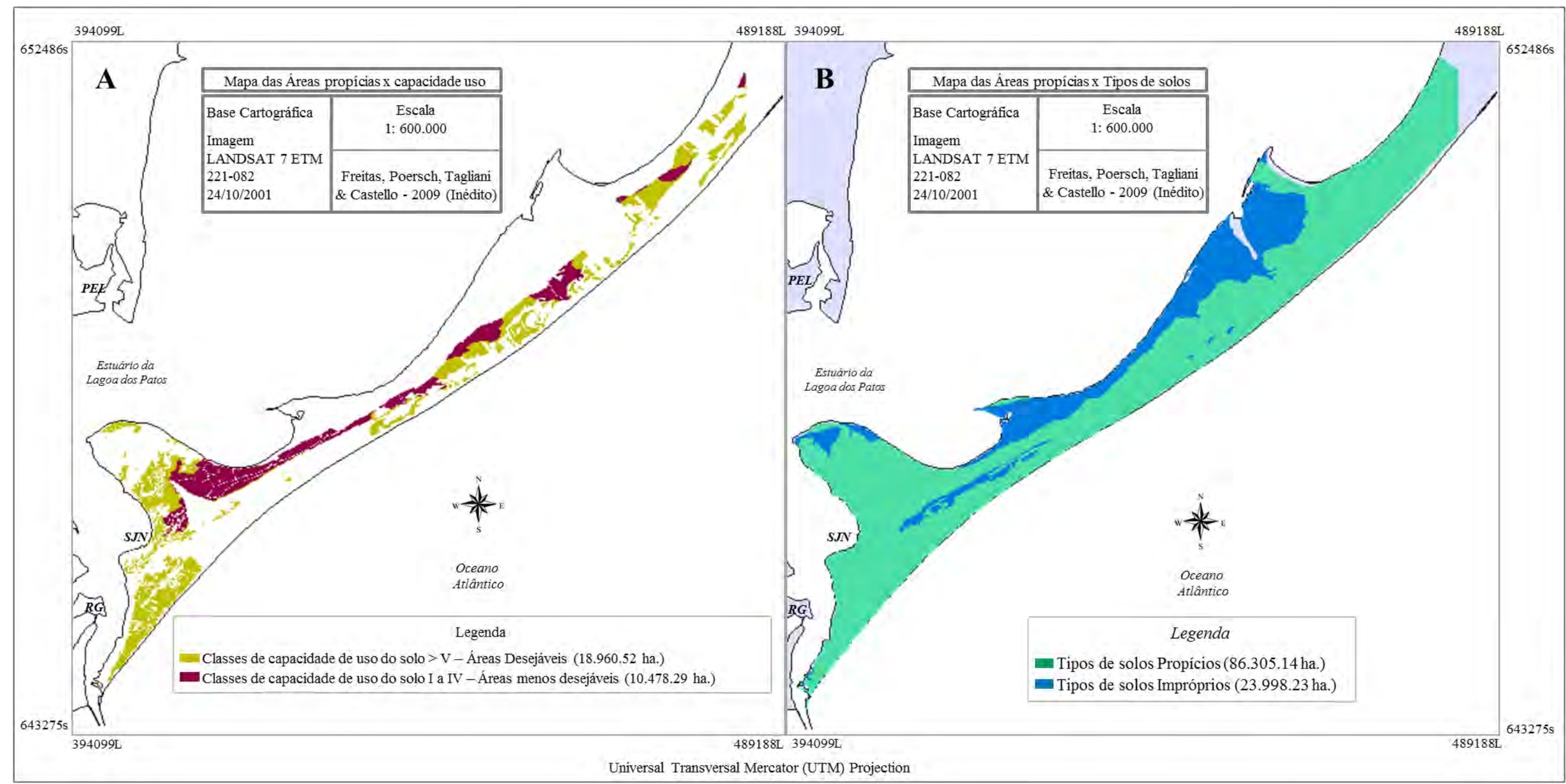

Figura 3 - A. Mapa temático representando as classes de capacidade de uso do solo local. B. Mapa temático de exclusão quanto ao tipo de solo. Figure 3 - A. Thematic map representing the classes of local soil usability. B. Thematic map of exclusion as to soil type. 


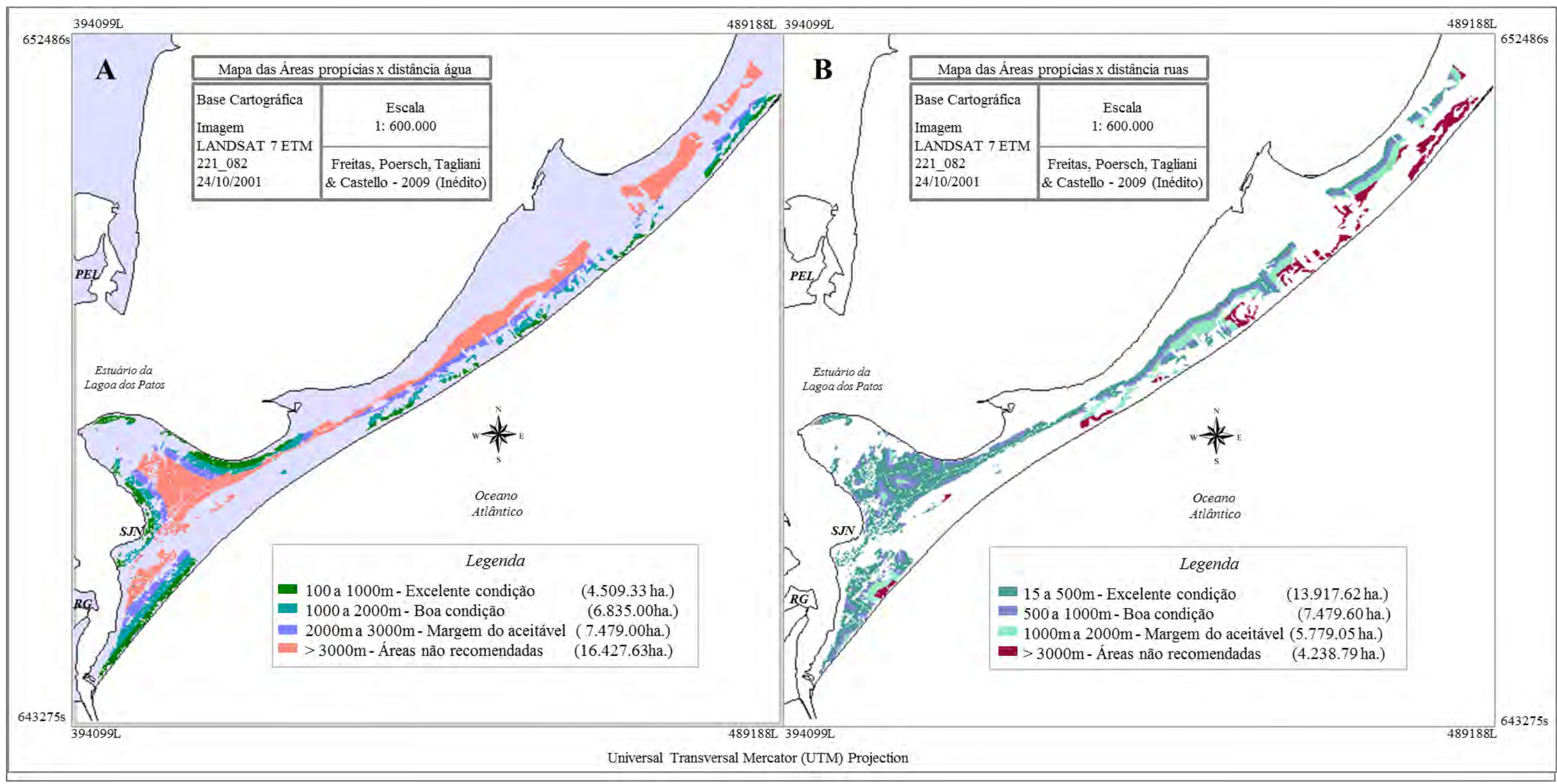

Figura 4 - A. Mapa temático representando a escala de atratividade para o critério distância da captação de água (Lagoa dos Patos e Oceano Atlântico). B. Mapa temático representando a escala de atratividade para o critério distância de vias públicas.

Figure 4 - A. Thematic map representing the attractiveness scale of distance water extraction (Patos Lagoon and the Atlantic Ocean). B. Thematic map representing the scale of distance of public roads attractiveness. 
$(46,60 \%)$ e os distintos valores obtidos como não recomendados $(13,49 \%)$, considerando o critério distância de estradas, corroboram com a afirmação de que para diferentes critérios teremos diferentes resultados e que somente uma análise individual, sem considerar outros critérios em conjunto (escala de atratividade), não credencia e não assegura que uma determinada área é realmente apta para qualquer atividade econômica. 3

Outro critério descritivo foi referente à distância para mercados consumidores. Como resultado de análise pode-se dizer que a produção gerada pelos cultivos no município será destinada ao município de Porto Alegre e pequena parte é consumida localmente e/ou vai para o município de Rio Grande. Já á distância até a capital do Estado é de cerca de $310 \mathrm{~km}$ e até Rio Grande o translado é feito através de barco (cerca de $5 \mathrm{~km}$ ). $\mathrm{O}$ fato de o principal centro consumidor ser distante não inviabiliza a comercialização, desde que seja feita uma despes$\mathrm{ca}$, armazenamento e transporte de forma higienicamente correta.
Foi também realizada a sobreposição destas informações, resultando em um mapa de atratividade final e destacando as áreas propícias para o cultivo de camarões marinhos em viveiros em São José do Norte (Figura 5).

Como resultado, obteve-se um mapa com a escala de atratividade variando de prioridade 1 a 4 , sendo que cerca de 5.300 ha $(16,84 \%)$ foram considerados com características mais atrativas, isto é, com excelentes condições; cerca de 14.600 ha $(46,78 \%)$ com condições boas; cerca de 10.600 ha $(33,95 \%)$ na margem do recomendado para a atividade; e por último, uma pequena fração, cerca de 760 ha $(2,43 \%)$, como áreas aptas, mas não recomendadas.

\section{Considerações Finais}

A análise das características geomorfológicas, disponibilidade de água, acessibilidade a mercado e insumos, mão de obra disponível, eletrificação e suporte técnico

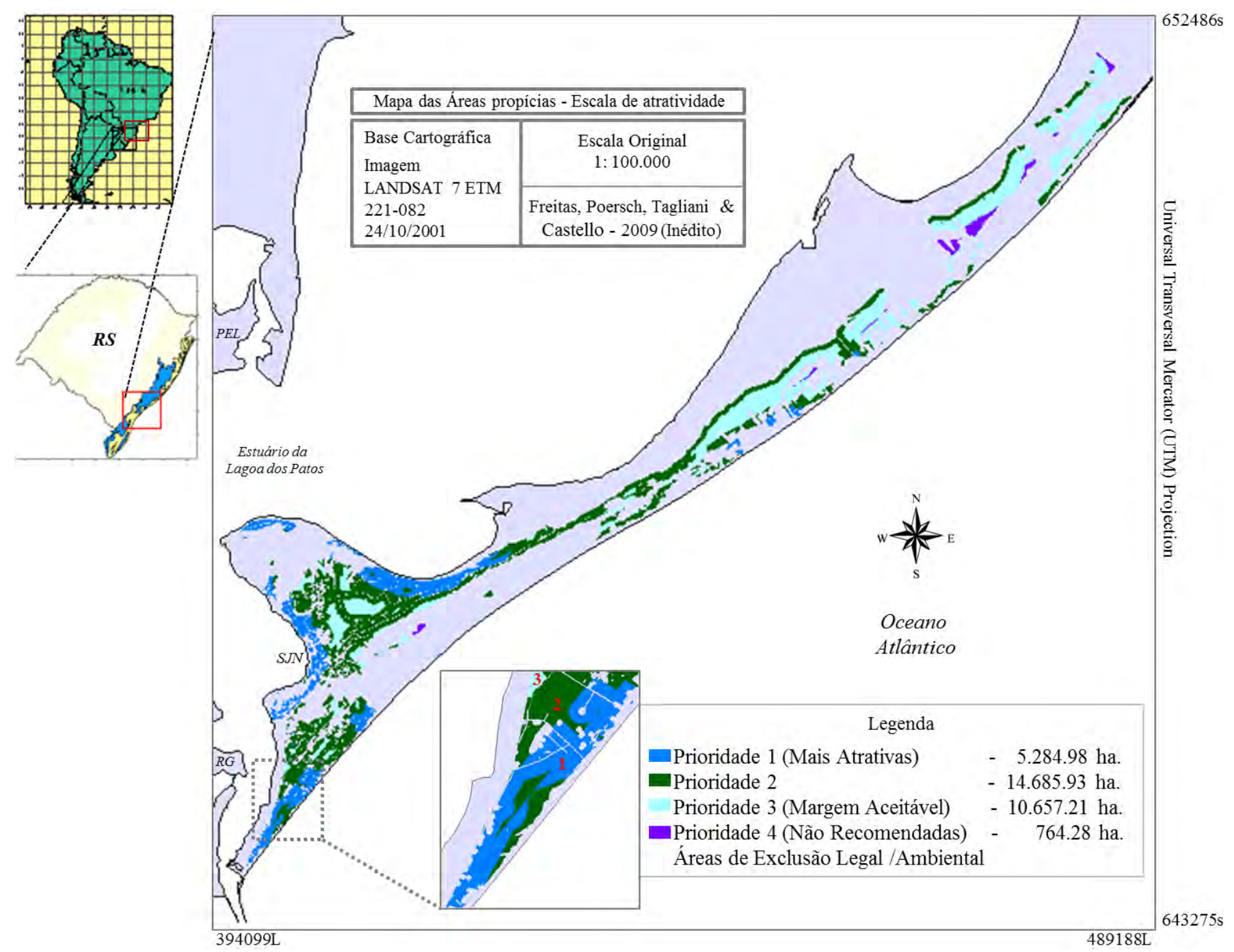

Figura 5 - Mapa de atratividade final - cultivo de camarões marinhos em viveiros (SJN).

Figure 5 - Final attractiveness map - Marine shrimp farm earth ponds (SJN). 
na região do estudo, indicaram uma condição amplamente favorável a carcinicultura marinha em viveiros de terra na região. As áreas classificadas com potencial alto e médio podem manter um ótimo nível de produção e, mesmo as áreas consideradas de baixo potencial, com diferentes demandas de investimento, podem alcançar os mesmos patamares produtivos.

Dentre as áreas que apresentam maior atratividade, a região próxima à boca da barra (destacada na Figura 5) apresenta grande potencial para a atividade, principalmente devido à proximidade tanto do mar como também da Lagoa dos Patos, o que facilita a captação da água para o cultivo. Além disso, embora seja uma área aparentemente isolada, há facilidade no acesso de certa forma, através da rodovia BR-101 e estradas vicinais. A região observa-se o predomínio de atividades agrícolas, indicando que já houve modificação no ambiente, reduzindo a chance de possíveis impactos causados pela implantação dos cultivos, que inclusive já existem naquele local. Por último, salienta-se que o uso das ferramentas disponíveis em SIG é eficaz no auxílio de tomada de decisão, especialmente no planejamento de usos da zona costeira. Talvez a maior contribuição dessas ferramentas seja o fato de que são flexíveis o suficiente para incorporar os aportes técnicos de várias áreas do conhecimento para a tomada de decisão.

A partir de uma base georreferenciada, é possível modelar as opções levando em conta também a percepção da comunidade envolvida como o assunto em foco. Isso diminui a subjetividade e valida de modo bastante democrático a tomada de decisão no processo de planejamento ambiental.

\section{Agradecimentos}

Este estudo foi financiado pelo Governo Federal do Brasil, Ministério da Ciência e Tecnologia (MCT / CT-HIDRO), Fundo Setorial de Recursos Hídricos / Ministério do Meio Ambiente - MMA / Conselho Nacional de Desenvolvimento Científico e Tecnológico - CNPq.

\section{References}

Aguilar-Manjarrez, J.; Ross, L.G. (1995) - Geographical information system (GIS) environmental models for aquaculture development in Sinaloa State. Aquaculture International, 3(2):103115. DOI: 10.1007/BF00117877

Baena, E.S. (2005) - A rentabilidade econômica da cultura do eucalipto e sua contribuição ao agronegócio brasileiro. Revista Conhecimento Interativo (ISSN: 1809-3442), 1(1):3-9, Faculdade Metropolitana de Curitiba, São José dos Pinhais, PR, Brasil. Disponível on-line em http://www.florestalouroverde.com.br/ florestalouroverde.com.br_rentabi lidade_eucalipto.pdf

Barbieri Júnior, R.C.; Neto, A.O. (2002) - Camarões marinhos: Engorda. 370p., Aprenda Fácil, Viçosa, MG, Brasil. ISBN: 8588216167

Beltrame, E.; Bonetti Filho J.; Bonetti, C. (2006) - Pre-selection of areas for shrimp culture in a subtropical Brazilian lagoon based on multicriteria hydrological evaluation. Journal of Coastal Research (ISSN: 0749-0208), SI39:1838-1842, UFSC, Florianópolis, SC, Brasil. Disponível on-line em http://siaiacad09.univali. br/ics2004/arquivos/388_beltrame.pdf
Buitrago, J.; Rada, M.; Hernández, H.; Buitrago, E. (2005) - A single use site selection technique, using GIS, for aquaculture planning: choosing locations for mangrove oyster raft culture in Margarita Island, Venezuela. Environmental Management. 35(5):544-556. DOI: 10.1007/s00267-004-0087-9

Capítoli, R.R.; Bemvenuti, C.E. (2004) - Distribuição do mexilhão dourado Limnoperna fortunei (Dunker, 1857) na área estuarina da Lagoa dos Patos e Canal São Gonçalo. Anais do VI Simpósio de Ecossistemas Brasileiros. 110(1):98-107, Academia de Ciências do Estado de São Paulo, São José dos Campos, SP, Brasil.

Chen, S.; Chen, L.; Liu, Q.; Li, X.; Tan, Q. (2005) - Remote sensing and GIS-based integrated analysis of coastal changes and their environmental impacts in Lingding Bay. Ocean \& Coast Manage, 48(1):65-83. DOI: 10.1016/j.ocecoaman.2004.11.004

Corbin, J.S.; Young, L. (1997) - Planning, Regulation, and Administration of Sustainable Aquaculture. In: Bardach, J. E. (Editor) - Sustainable Aquaculture, pp. 201-233, John Wiley \& Sons, Inc, New York, USA. ISBN: 978-0471148296. Disponível on-line em http://cabdirect.org/abstracts/19981806061.html

Cordazzo, C.V.; Seeliger, U. (1998) - Guia Ilustrado da Vegetação Costeira do Extremo Sul do Brasil. 275p., Editora da FURG, Rio Grande, RS, Brasil. ISBN: 8585042222.

Crepani, E.; Medeiros, J.S. (2003) - Carcinicultura em apicum no litoral do Piauí: uma análise com sensoriamento remoto e geoprocessamento. Anais eletrônicos, Simpósio Brasileiro De Sensoriamento Remoto - XI, INPE, Belo Horizonte, MG, Brasil. Disponível on-line em http://marte.dpi.inpe.br/col/ltid.inpe.br/sbsr/2002/ 11.13.17.36/doc/13_146.pdf

Cunha, N.G.; Silveira, R.J.C.; Severo, C.R.S. (1996) - Estudo dos solos do município de Rio Grande. 74p., Universitária/UFPel, Pelotas, RS, Brasil. Disponível on-line em http://www.infoteca.cnptia. embrapa.br/bitstream/doc/737762/6/RioGrande.pdf

Dennis, M.; Tammy, T.; Baldwin, K.; Kevin, F. (2003) - Aquaculture development potential in Arizona: a GIS-based approach. World Aquaculture (ISSN: 1041-5602). 34(4):32-35, World Aquaculture Society, Baton Rouge, LA, USA. Disponível on-line em https://www.was.org/magazine/ArticleContent.aspx?Id=147

FAO (1997) - Support to special plan for prawn and shrimp farming: site selection towards sustainable shrimp aquaculture. Food and Agriculture Organization (FAO). Bangkok, Tailândia. Disponível on-line em http://www.fao.org/docrep/field/377199.htm

FAO (2010) - The state of world fisheries and aquaculture. $218 \mathrm{p}$., Food and Agriculture Organization (FAO), Roma, Italia. ISBN: 978-9251066751. Disponível on-line em http://www.fao.org/docrep/013/i1820e/i1820e.pdf

Figueiredo, A.S.; Calliari, L.J. (2006) - Sedimentologia e suas Implicações na morfodinâmica das Praias adjacentes às desembocaduras da linha de costa do Rio Grande do Sul. Gravel (ISSN: 1678-5975), 4(1):73-87, UFRGS, Porto Alegre, RS, Brasil.

Frankic, A. (1998) - A framework for planning sustainable development in coastal regions: an island pilot project in Croatia. 124p., Dissertação, Virginia Institute of Marine Science, Virgínia, USA. Disponível on-line em http://web.vims.edu/library/ Frankic/Frankic.pdf

Freitas, D.M.; Tagliani, P.R.A. (2007) - Spatial Planning of Shrimp Farming in the Patos Lagoon Estuary (Southern Brazil): An Integrated Coastal Management Approach. Journal of Coastal Research, SI47:136-140. DOI: 10.2112/1551-5036-47.sp1.136

Freitas, R.R.; Vinatea, L.; Netto, S. (2009) - Analysis of the marine shrimp culture production chain in Southern Brazil. Anais Academia Brasileira de Ciências, 81(2):287-295. DOI: 10.1590/S0001-37652009000200015

Freitas, R.R.; Tagliani, C.R.A.; Poersch, L.H.D.S.; Tagliani, P.R.A. (2009) - Gestão de ambientes costeiros: uso de SIG como apoio a decisão na implantação de fazendas de camarões marinhos, I- 
lha da Torotama, Revista da Gestão Costeira Integrada 9(3):4554 DOI: $10.5894 /$ rgci164

Garcia, C.A.E. (1998) - Características hidrográficas. In: U. Seeliger, C. Odebrecht \& J.P. Castello (Eds), Os Ecossistemas Costeiro e Marinho do Extremo Sul do Brasil, pp.18-21. Editora Ecoscientia. Rio Grande, RS, Brasil.

GESAMP (2000) - Principality of Monaco: report of the 30th Session. 68p., GESAMP (IMO/FAO/UNESCO-IOC/WMO/WHO/ IAEA/UN/UNEP Join group of experts on the Scientific Aspects of Marine Environmental Protection), Reports and Studies $\mathrm{n}^{\mathrm{o}}$. 69, International Atomic Energy Agency, Vienna, Austria. Disponível on-line em http://www.gesamp.org/publications/ publicationdisplaypages/rs69

Giap, D.H.; Yi, Y.; Yakupitiyage, A. (2005) - GIS for land evaluation for shrimp farming in Haiphong of Vietnam. Ocean Coast Manage, 48(1):51-63. DOI: 10.1016/j.ocecoaman. 2004.11.003

Gianuca, K.S.; Tagliani, C.R.A. (2012) - Análise em um Sistema de Informação Geográfica (SIG) das alterações na paisagem em ambientes adjacentes a plantios de pinus no Distrito do Estreito, município de São José do Norte, Brasil. Revista de Gestão Costeira Integrada, 12(1):43-55. DOI: 10.5894/rgci285

Gowing, J.; Ocampo-Thomason, P. (2007) - Exploratory analysis of the comparative environmental costs of shrimp farming and rice farming in coastal areas. In: D.M. Bartley, C. Brugère, D. Soto, P. Gerber \& B. Harvey, B. (eds.), Comparative assessment of the environmental costs of aquaculture and other food production sectors: methods for meaningful comparisons, pp.201220, FAO (Food and Agriculture Organization of the United Nations), Rome, Itália. ISBN: 978-9251058633. Disponível online em ftp://ftp.fao.org/ docrep/fao/010/a1445e/a1445e.pdf

Hossain, M.S.; Chowdhury, S.R.; Das, N.G.; Rahaman, M.M. (2007) - Multi-criteria evaluation approach to GIS-based landsuitability classification for tilapia farming in Bangladesh. $A$ quaculture International, 15(5):425-443. DOI: 10.1007/s10499007-9109-y

Kampel, M.; Amaral, S.; Soares, M.L.G. (2005) - Imagens CCD/ CBERS e TM/Landsat para análise multi-temporal de manguezais no nordeste brasileiro: um estudo no litoral do Estado do Ceará. Anais eletrônicos, XII Simpósio Brasileiro de Sensoriamento Remoto (SBSR), pp.979-986, Goiânia, Goiás, Brasil. Disponível on-line em http://www.obt.inpe.br/cbers/cbers_XIISBSR/408_KAS_ XIISBSR_Final.pdf

Kapetsky, J.M.; Hill, J.M.; Worthy, L.D.; Evans, D.L. (1988) - A geographical information system for catfish farming development. Aquaculture, 68(4):311-320. DOI: 10.1016/00448486(88)90245-1

Karthika, M.; Surib, J.; Neelam S.; Biradar, R.S. (2005) - Brackish water aquaculture site selection in Palghar Taluk, Thane district of Maharashtra, India, using the techniques of remote sensing and geographical information system. Aquacultural Engineering, 32(2):285-302. DOI: 10.1016/j.aquaeng.2004.05.009

Lee, D.O.C.; Wickins, J.F. (1997) - Cultivo de crustáceos. 466p., Acribia S.A., Zaragoza, Espanha. ISBN: 978-8420007960

Lepsch, I.F.; Bellinazzi Jr., R.; Bertolini, D.; Espíndola, C.R. (1983) - Manual para levantamento utilitário do meio físico e classificação de terras no sistema de capacidade de uso, 175p., Sociedade Brasileira de Ciência do Solo, Campinas, SP, Brasil.

Longdill, P,C.; Healy, T.R.; Black, K.P. (2008) - An integrated GIS approach for sustainable aquaculture management area site selection. Ocean \& Coastal Management, 51(8-9):612-624. DOI: 10.1016/j.ocecoaman.2008.06.010.

Mcleod, I.; Pantus, F.; Preston, N. (2002) - The use of geographic information system for land-base aquaculture planning. Aquaculture Research, 33(4):241-250. DOI: 10.1046/j.1355557x.2001.00667.x
Moles, P.; Bunge, J. (2002) - Shrimp farming in Brazil: an industry overview. 26p., World Bank / FAO (Food and Agriculture Organization of the United Nations) / WWF (World Wildlife Fund) / NACA (Network of Aquaculture Centres in AsiaPacific) Consortium Program on Shrimp Farming and the Environment. Disponível on-line em http://library.enaca.org/Shrimp/Case/ LatinAmerica/Brazil/ShrimpFarmingBrazil.pdf

Möller, O.; Fernandes, E. (2010) - Hidrologia e Hidrodinâmica. In: U. Seeliger \& C. Odebrecht (eds.), O Estuário da Lagoa dos Patos: Um século de transformações, pp.17-27, FURG, Rio Grande, RS, Brasil.

Moura, A.R.L.U.; Sá, L.T.L.; Lima, G.M.; Alves, F.P. (2002) - Utilização de técnicas de sensoriamento remoto na identificação de áreas estuarinas do Canal de Santa Cruz e Rio Jaguaribe - Pernambuco. Anais eletrônicos, Congresso Brasileiro de Cadastro Técnico Multifinalitário (COBRAC), Florianópolis, SC, Brasil, Disponível on-line em http://geodesia.ufsc.br/Geodesia-online/ arquivo/cobrac_2002/043/043.htm

Oliveira, A.O.; Calliari L.J. (2006) - Morfodinâmica da Praia do Mar Grosso, São José do Norte/RS. Gravel (ISSN: 1678-5975), 4(1):23-36, UFRGS, Porto Alegre, RS, Brasil. Disponível on-line em http://www.ufrgs.br/gravel/4/Gravel_4_02.pdf

Peixoto, S.; Wasielesky J.R.; Cavalli, R.O.; Santos, M.H.S.; Poersch, L.H.S. (2005) - Diretrizes para o desenvolvimento responsável da carcinicultura na região do estuário da Lagoa dos Patos, Rio Grande do Sul, Brasil. Gerenciamento Costeiro Integrado, 4:1-4, Itajaí, SC, Brasil.

Pérez, O.M.; Telfer, T.C.; Beveridge, M.C.M.; Ross, L.G. (2002) Geographical Information Systems (GIS) as a Simple Tool to Aid Modelling of Particulate Waste Distribution at Marine Fish Cage Sites. Estuarine, Coastal and Shelf Science, 54(4):761768. DOI: $10.1006 /$ ecss. 2001.0870

Pérez, O.M.; Telfer, T.C.; Ross, L.G. (2003) - Use of GIS-Based Models for Integrating and Developing Marine Fish Cages within the Tourism Industry in Tenerife (Canary Islands). Coastal Management, 31(4):355-366. DOI: 10.1080/ 08920750390232992

Poersch, L.; Cavalli, R. O.; Wasielesky Junior, W. (2006) - Perspectivas para o desenvolvimento dos cultivos de camarões marinhos no estuário da Lagoa dos Patos, RS. Ciência Rural (ISSN: 01038478), 36(4):1337-1343, Universidade Federal de Santa Maria, Santa Maria, RS, Brazil . DOI: 10.1590/S010384782006000400051

Poli, C.R.; Borghetti, J.R.; Grumann, A. (2000) - Situação Atual da Aqüicultura na Região Sul. In: C.R. Poli \& A. Grumann (eds.), Aqüicultura no Brasil: Bases para um desenvolvimento sustentável, pp. 323-351, CNPQ/ Ministério da Ciência e Tecnologia, Florianópolis, SC, Brasil. ISBN: 8587632094.

Prein, M.; Ahmed, M. (2000) - Integration of aquaculture into smallholder farming systems for improved food security and household nutrition. Food and nutrition bulletin (ISSN: 1564-8265), 21(4):466-471, The United Nations University, Boston, USA. Disponível on-line em http://nsinf.publisher.ingentaconnect.com/ content/nsinf/fnb/2000/00000021/00000004/art00024

Primavera, J.H. (2006) - Overcoming the impacts of aquaculture on the coastal zone. Ocean \& Coastal Management, 49(9-10):531545. DOI: 10.1016/j.ocecoaman.2006.06.018.

Pullin, R.S.V.; Rosenthal, H.; Maclean, J.J. (eds.) (1993) - Environment and aquaculture in developing countries. 359p., International Center for Living Aquatic Resources Management, Manila, Filipinas; Deutsche Gesellschaft für Technische Zusammenarbeit, Frankfurt, Alemanha. ISBN: 9718709266. Disponível on-line em http://www.worldfishcenter.org/libinfo/Pdf/Pub CP6 31.pdf

Prost, M. T. (2001) - Manguezais paraenses: recursos naturais, usos sociais e indicadores para a sustentabilidade. 62p., Relató- 
rio Final, Museu Paraense Emílio Goeldi, Belém, PA, Brasil. Disponível on-line em http://hdl.handle.net/10625/31220

Radiarta, I.N.; Saitoh, S.; Miyazono, A. (2008) - GIS-based multicriteria evaluation models for identifying suitable sites for Japanese scallop (Mizuhopecten yessoensis) aquaculture in Funka Bay, southwestern Hokkaido, Japan. Aquaculture, 284(14):127-135. DOI: 10.1016/j.aquaculture.2008.07.048

Rajitha, K.; Mukherjee, C.K.; Chandran, R.V. (2007) - Applications of remote sensing and Gig for suitable management of shrimp culture in India. Aquacultural Engineering, 36(1):1-17. DOI: 10.1016/j.aquaeng.2006.05.003

Salam, M.A.; Khatun, N.A.; Ali, M.M. (2005) - Carp farming potential in Barhatta Upazilla, Bangladesh: a GIS methodological perspective. Aquaculture, 245(1-4):75-87. DOI: 10.1016/j.aquaculture.2004.10.030

Souto, M.V.S.E; Amaro, V.E. (2005) - Aplicação das técnicas de geoprocessamento para o mapeamento da Vulnerabilidade Natural para a região da Ponta do Tubarão, litoral setentrional do Estado do Rio Grande do Norte, município de Macau. Anais eletrônicos, XII Simpósio Brasileiro de Sensoriamento Remoto, pp. 2773-2778, Goiânia, GO, Brasil. Disponível on-line em http://marte.sid.inpe.br/col/ltid.inpe.br/sbsr/2004/11.19.18.35/doc/2773. pdf

Tagliani, C.R.A., Vicens, R.S. (2003) - Mapeamento da vegetação e uso do solo nos entornos do estuário da Laguna dos Patos, RS, utilizando técnicas de processamento digital de imagem do SIG SPRING. Anais eletrônicos, XI Simpósio Brasileiro de Sensoriamento Remoto, pp.1461-1468, Belo Horizonte, MG, Brasil.
Tagliani, P.R.A.; Silva, T.S. (2011) - As macro funções ambientais e o planejamento espacial da região. pp. 161-168, In: Paulo Roberto Armanini Tagliani. (Org.). Ecologia da paisagem da restinga da Lagoa dos Patos: uma contribuição para o manejo e conservação da reserva da biosfera. Editora da FURG, Rio Grande, RS, Brasil.

Torres, C.; Andrade, C. (2010) - Processo de decisão de Análise Espacial na selecção de áreas óptimas para a Aquacultura Marinha: O exemplo da Ilha da Madeira. Setembro de 2010. Revista da Gestão Costeira Integrada 10(3):321-330. DOI: 10.5894/rgci180

Vitalli, P.D.L.; Zakia, M.J.B.; Durigan, G. (2009) - Considerações sobre a legislação correlata à zona-tampão de unidades de conservação no brasil. Ambiente \& Sociedade, 12(1):67-82. DOI: 10.1590/S1414-753X2009000100006.

Völcker, C.M., Scott, P. (2008) - SIG e sensoriamento remoto para a determinação do potencial da aquicultura no Baixo São João RJ. Sistemas e Gestão (ISSN: 1980-5160), 3(3):196-215. UFF, Niterói, RJ, Brasil. Disponível on-line em http://www.revistasg.uff.br/ index.php/sg/article/view/SGV3N3A3/59

Ucha, J.M.; Hadlich, G.M.; Carvalho, E.G.S. (2011) - Manguezais e carcinicultura no baixo sul da Bahia, p. 5002-5008, Anais eletrônicos, XV Simpósio Brasileiro de Sensoriamento Remoto. MCT/INPE, Curitiba, PR, Brasil. Disponível on-line em http://www.dsr.inpe.br/sbsr2011/files/p0354.pdf 